\title{
Current Status of Cardiovascular Imaging in Germany: Structured Data from the National Certification Program, ESCR Registry, and Survey among Radiologists
}

\author{
Status der kardiovaskulären Bildgebung in Deutschland: \\ Strukturierte Datenerhebung auf Basis des nationalen \\ Zertifizierungsprogramms, des ESCR-Registers und einer Umfrage \\ unter Radiologen
}

Authors

Malte Maria Sieren', David Maintz ${ }^{2}$, Matthias Gutberlet ${ }^{3,4}$, Gabriele Anja Krombach ${ }^{5}$, Fabian Bamberg ${ }^{6}$, Peter Hunold ${ }^{7}$, Lukas Lehmkuhl $^{8}$, Katharina Fischbach ${ }^{9}{ }^{10}$, Sebastian Reinartz ${ }^{11}$, Gerald Antoch ${ }^{12}$, Jörg Barkhausen ${ }^{1}$, Jörn Sandstede ${ }^{13,}{ }^{14}$, Martin Völker ${ }^{15}$, Claas Naehle ${ }^{16}$

Affiliations

1 Department of Radiology and Nuclear Medicine, University Hospital Schleswig-Holstein Campus Lübeck, Lübeck, Germany

2 Department for Interventional and Diagnostic Radiology, University Hospital Cologne, Germany

3 Department for Diagnostic and Interventional Radiology, Heart Center Leipzig - University Leipzig, Germany

4 Steering Committee Chair MRCT-Registry of the ESCR, ESCR, Vienna, Austria

5 Department of Diagnostic and Interventional Radiology, University-Hospital Gießen, Germany

6 Department for Diagnostic and Interventional Radiology, University Hospital Freiburg, Germany

7 n/a, FOKUS Radiologie \& Nuklearmedizin, Göttingen, Germany

8 Department for Diagnostic and Interventional Radiology, RHÖN Clinic, Campus Bad Neustadt, Germany

9 Diagnostische Radiologie, Otto-von-Guericke-Universität, Magdeburg, Germany

10 Department of Radiology and Nuclear Medicine, University Hospital Magdeburg, Otto von Guericke University, Magdeburg, Germany

11 Department for Diagnostic and Interventional Radiology, University Hospital Aachen, Germany

12 Department for Diagnostic and Interventional Radiology, Medical Faculty, Heinrich Heine University Düsseldorf, University Hospital Düsseldorf, Germany

13 Hamburg Wördemanns Weg, Radiologische Allianz, Hamburg, Germany

14 Berufsverband der deutschen Radiologen e.V. (BDR), Munich, Germany

15 Bereich Wissenschaft, Nachwuchsförderung, Zertifizierung, German Roentgen Society “Deutsche Röntgengesellschaft”, Berlin, Germany

16 Department for Interventional and Diagnostic Radiology, University Hospital Cologne, Germany
Key words

cardiovascular imaging, ESCR Registry, survey, quality

assessment, certification program

received 29.03.2021

accepted 09.07.2021

published online 12.08.2021

Bibliography

Fortschr Röntgenstr 2022; 194: 181-191

DOI 10.1055/a-1554-9236

ISSN 1438-9029

(c) 2021. Thieme. All rights reserved.

Georg Thieme Verlag KG, Rüdigerstraße 14,

70469 Stuttgart, Germany

Correspondence

Dr. Malte Sieren

Department of Radiology and Nuclear Medicine, University

Hospital Schleswig-Holstein Campus Lübeck, Ratzeburger

Allee 160, 23562 Lübeck, Germany

Tel.: +49/1 76/93112005

malte.sieren@uksh.de

\section{ZUSAMMENFASSUNG}

Ziel Vor dem Hintergrund der stark zunehmenden Bedeutung der kardiovaskulären Schnittbildgebung (KVB) in den aktuellen Leitlinien soll diese Arbeit einen umfassenden Überblick über die von radiologischen Einrichtungen in Deutschland angebotene KVB geben.

Material und Methoden Die Daten wurden aus der Datenbank des nationalen Zertifizierungsprogramms der Deutschen Röntgengesellschaft (DRG) von 2015-2021 extrahiert. Für den Zeitraum 2019 wurden eine bundesweite OnlineBefragung unter radiologischen Einrichtungen (Universitätskliniken, nichtuniversitäre Krankenhäuser und niedergelassene Ärzte) durchgeführt sowie Daten aus dem Register der European Society of Cardiovascular Radiology (ESCR) extra- 
hiert. Zu den Kernpunkten der Datenerhebung gehörten die Anzahl der für KVB zertifizierten Zentren und Personen, die durchgeführten kardialen CT- und MRT-Untersuchungen, die Befundungsgewohnheiten und die Teilnahme am ESCR-Register.

Ergebnisse 71 Zentren und 1278 Personen, jeweils mit einem deutlichen Anstieg seit 2015, waren für KVB von der DRG zertifiziert. Laut der Umfrage wurden in den teilnehmenden Einrichtungen insgesamt 69286 CT- und 64281 MRT-Untersuchungen jährlich durchgeführt. Die Daten aus der Umfrage und dem ESCR-Register zeigten, dass die Befundung der Untersuchungen meist durch Radiologen, in geringerem Maße in gemeinsamen Konsensus-Meetings mit nichtradiologischen Fachdisziplinen erfolgte. Die Teilnahmequote am ESCR-Register lag bei $48 \%$.

Schlussfolgerung Diese umfassende Analyse zeigt, dass eine qualitativ hochwertige KVB durch Radiologen flächendeckend verfügbar ist. Die aktuellen Herausforderungen bestehen darin, die beste medizinische und technische Qualität in der KVB für die Patientenversorgung durch Radiologen sicherzustellen und die wirtschaftliche Nachhaltigkeit im deutschen Gesundheitssystem zu gewährleisten, um den prognostizierten, erheblichen Bedarf an kardiovaskulärer Bildgebung in der Zukunft zu decken.

\section{Kernaussagen}

- Hochqualifizierte KVB durch Radiologen ist bundesweit flächendeckend verfügbar.

- Hochqualifizierte Expertise ist in Universitätskliniken, Krankenhäusern und niedergelassenen Praxen breit vertreten.

- Zertifizierungsprogramme tragen erfolgreich zur Verbreitung und Vertiefung der KVB-Expertise bei.

- Das ESCR-Register ist ein etabliertes internationales Instrument zur Dokumentation der KVB.

\section{ABSTRACT}

Purpose In the light of the increasing importance of cardiovascular cross-sectional imaging in current guidelines, the goal of this study is to provide a comprehensive overview of cardiovascular imaging (CVI) offered by radiological institutions across Germany.
Materials and Methods Data were extracted from the national certification program database of the German Roentgen Society (DRG) from 2015-2021. A nationwide online survey among radiology institutes (university hospitals, non-university hospitals, and private practices) was conducted for 2019, and data was extracted from the European Society of Cardiovascular Radiology (ESCR) registry. The data collection's key points included the number of centers and individuals certified for CVI, the number of cardiac CT and MRI examinations performed, the reporting habits, and the participation in the ESCR registry.

Results 71 centers and 1278 persons, both with a substantial increase since 2015, were registered and certified by the DRG to perform CVI. According to the survey, a total of 69,286 CT and 64,281 MRI examinations were performed annually. Data from the survey and the ESCR registry indicated that reporting was mostly done solely by radiologists or, to a lesser degree, in joint consensus meetings with non-radiologists. The overall participation rate in the ESCR registry was $48 \%$ among the survey's participants.

Conclusion This comprehensive analysis demonstrates that high-quality CVI by radiologists is available nationwide. The current challenges are to provide the best medical and technical quality of CVI by radiology for patient care and to ensure economic sustainability in the German health care system to accommodate the predicted substantial need for CVI in the future.

\section{Key Points}

- High-quality advanced CVI service by radiologists is available nationwide.

- Highly qualified specialist knowledge is widely represented from university to private practices.

- Certification programs successfully contribute to the dissemination \& deepening of CVI expertise.

- The ESCR registry is an established international tool for the documentation of CVI.

\section{Citation Format}

- Sieren M, Maintz D, Gutberlet M et al. Current Status of Cardiovascular Imaging in Germany: Structured Data from the National Certification Program, ESCR Registry, and Survey among Radiologists. Fortschr Röntgenstr 2022; 194: 181-191

\section{Introduction}

Over the last decade, cross-sectional cardiovascular imaging, i. e., computed tomography (CT) and magnetic resonance imaging (MRI), have transitioned from an up-and-coming field to modalities deeply rooted in clinical practice.

The growing body of evidence in the pertinent literature has emphasized cross-sectional cardiovascular imaging (CVI) in a plethora of national and international guidelines [1-3], which resulted in the consolidation of existing indications as well as the definition of new ones. Particularly in coronary artery disease, CT and
MRI are noninvasive, low-risk alternatives that partly replace cardiac catheterization, providing new parameters and differential diagnoses that are otherwise not available [4, 5]. This has also led to a broad echo in the national radiological community $[6,7]$. Against this background, a substantial increase in the demand for CVI imaging is expected [8].

Within the German Roentgen Society (Deutsche Röntgengesellschaft e. V., DRG), CVI is anchored with the Cardiovascular Imaging working group (WG CVI; AG Herz- und Gefäßdiagnostik). The DRG aims to certify radiologists with special expertise in performing and interpreting CVI studies. For this purpose, a certifica- 
tion program for individuals and institutions as well as a training program accessible for German-speaking radiologists has been established [9]. Moreover, a registry for cardiovascular CT and MRI examinations has been maintained through international cooperation with the European Society of Cardiovascular Radiology (ESCR) since 2012 for documentation and accreditation purposes, to identify centers for initiation of multicenter trials, to substantiate examination figures, ensure the highest quality of patient care, and to promote CVI expertise beyond national borders.

The aim of this study was to assess the national availability of high-quality, certified cardiovascular imaging in Germany as well as the characteristics of the radiological infrastructure and clinical routines: Firstly, by analyzing the DRG database for certified centers and individuals, secondly, by conducting a nation-wide online survey among radiology institutes, and thirdly, by extracting data from the ESCR registry.

\section{Methods}

\section{Data acquisition of certified centers and personnel}

The number of certified centers, CVI-certified radiologists, and members of the WG CVI was extracted from the DRG database for each year from January 1, 2015 until February 1, 2021. Institutions were assigned to a region in Germany based on the first two digits of their respective postcode. The number of postcode regions with access to a certified center was documented. Individuals' certification levels are graded with increasing expertise from Q1 (basic knowledge) to Q3 (comprehensive knowledge, instructor). Each Q-level can be acquired for CT and MRI separately. A detailed description of the requirements for each level can be found elsewhere [9].

\section{Development of the questionnaire and distribution}

Members of the WG CVI and the DRG developed the survey. The questionnaire was published online twice, between August 24 and October 31, 2020 and between January 11 and February 1, 2021, employing a software designed to conduct online surveys (SurveyMonkey, SurveyMonkey Europe Sarl, Luxembourg).

To assure generalizability, the survey participants were recruited via the email distributor of the Conference of Chairs of University Hospital Radiology (Konferenz der Lehrstuhlinhaber, KLR), the Chief Physician Forum of the DRG (CAFRAD), and via the email distributor of the Heads of Institutions of the Professional Association of German Radiologists (Berufsverband der Deutschen Radiologen e. V., BDR). German university hospitals and certified centers were once reminded by telephone to participate in the survey. An independent central office received all answers to the survey. Participants were encouraged to provide their institution's name with assurances of confidentiality and strict adherence to data protection guidelines. For responses, which did not provide the name of the institution, duplicates were excluded by matching the given answers' IP addresses and redundancies. Due to the nature of the survey, ethics committee approval was not necessary.

\section{Structure of the questionnaire}

The questionnaire included 18 questions in total, referring to the following items. All data were related to the year 2019.

\section{Characterization of the institutions and certified personnel}

The first two questions addressed the location of the institution and its structure. Participants were asked to name their institution and specify their location with a postal code in a free text box. Possible answers regarding the institutional type were i) university hospital, ii) non-university hospital, iii) private practice.

The following nine questions asked for the number of Q1- to Q3-certified radiology specialists in the department. The number of CVI-certified staff was requested for CT, MRI, and combined for CT and MRI, respectively.

\section{Number of examinations and reporting standards}

Two questions referred to the number of cardiovascular CT and MRI examinations per institution. Here, planning examinations for TAVI and PVI interventions were explicitly included. The next two questions addressed the reporting situation of cardiovascular CT and MRI in the respective department. For both modalities, the respondents could choose between reporting performed solely by radiologists, joint reporting by radiologists and non-radiologists, and reporting by non-radiologists alone.

Next, participants were asked whether examinations are submitted to the international MRCT ESCR registry (14) for the documentation of radiological cross-sectional examinations. In case of a positive answer, the proportion of examinations entered in the registry could be indicated. The categorical answer options, i) $1-25 \%$, ii) $26-50 \%$, iii) $51-75 \%$ and iv) $76-100 \%$, were available.

\section{Communication with the DRG and the WG CVI}

Finally, the respondents were asked about possible topics on which the DRG and the WG CVI should provide information as a matter of priority. The following options were given: i) cooperation with colleagues, ii) certification, iii) technology, and iv) medical education and training.

\section{Data from the ESCR Registry}

The number of institutions in Germany entering examinations in the ESCR registry was determined from the registry's database. The data on the reporting habits of cardiac CT and cardiac MRI examinations were extracted from the registry. Possible categories were i) reporting by a radiologist, ii) consensus reading (radiologist \& cardiologist), iii) reporting by a cardiologist, iv) separate reading, or v) other.

\section{Statistics}

Statistical analyses were performed using SPSS (v25.0, IBM Corp., United States).

Descriptive statistics with respective percentages were used. If applicable, the median with [25\%; $75 \%$ range] was given. Non- 


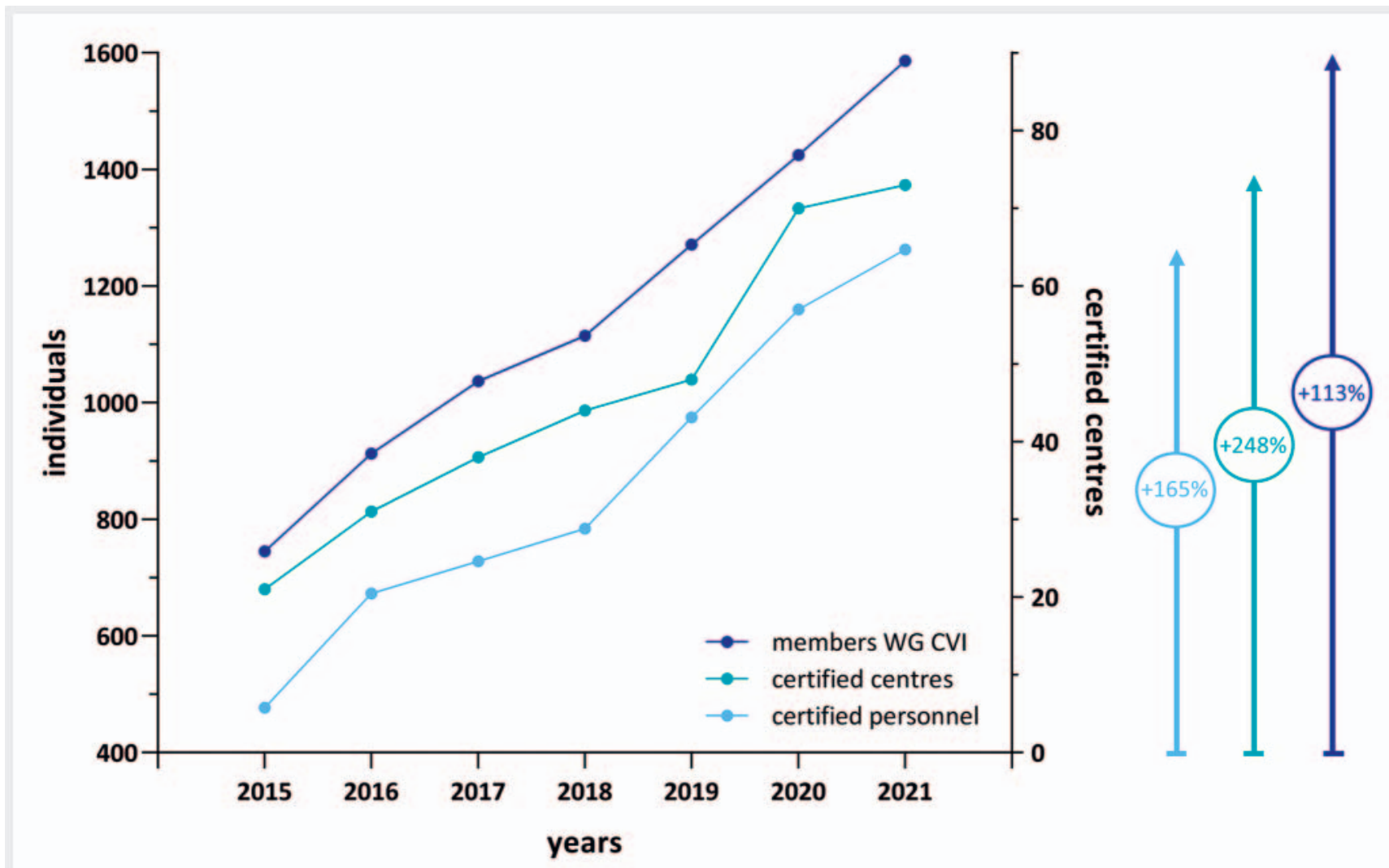

- Fig. 1 Number of certified centers in Germany, certified individuals (combined Q1-3, with increasing expertise) and members of the Cardiovascular Imaging Working Group (WG CVI) from 2015 to 2021. The growth figures in percent refer to the period from 2015 to 2021 for each subgroup.

- Abb. 1 Anzahl der zertifizierten Zentren in Deutschland, der zertifizierten Personen (kombiniert Q1-3, mit steigender Expertise) und der Mitglieder der Arbeitsgruppe Herz- und Gefäßbildgebung von 2015-2021. Die Wachstumszahlen in Prozent beziehen sich auf den Zeitraum von 2015-2021 für jede Untergruppe.

parametric data were analyzed using the Mann-Whitney $U$ test for two groups. To minimize error due to multiple testing, the Kruskal-Wallis test was employed when more than two groups were present. A P-value of $<0.05$ was considered statistically significant.

\section{Results}

\section{Locoregional distribution of certified centers and personnel}

In total, 71 centers in Germany and 1278 persons were certified by the DRG, and the WG CVI had 1612 registered members on February 1, 2021. Of the certified radiologists, 902 individuals were certified as Q1 (71\%), 227 as Q2 (18\%) and 149 as Q3 (12\%). The data of the previous years with illustration of the corresponding growth can be found in - Fig. 1. Of the 99 postcode regions in Germany, a total of 56 (57\%) had direct access to a certified center. Two centers were located in nine of these regions, and three centers in four regions. A corresponding overview of the regional distribution of certified centers with capture areas can be found in > Fig. 2 .

\section{Evaluation of the Questionnaire}

\section{Characterization of the institutions and certified personnel}

A total of 184 responses were received, of which 30 were from university hospitals, 76 from non-university hospitals and 78 from private practices. Answers were received from 72 (73\%) of the 99 German postcode regions.

In total, the survey captured 695 certified professionals, representing $71 \%$ of the total number of registered individuals with certification in 2019. These were divided into 427 Q1 (61\% of the surveyed population; 249 CT\&MRI, 90 CT only, 88 MRI only), 173 Q2 (25\%; 107 CT\&MRI, 38 CT only, 28 MRI only) and 95 Q3 certified individuals (14\%; 77 CT\&MRI, 9 CT only, 9 MRI only). Of those included in the survey, 262 individuals (38\%) worked at university hospitals, 289 (42\%) at non-university hospitals, and $144(21 \%)$ at private practices $(P<0.01)$. An illustration of the data can be found in > Fig. 3.

Number of examinations and reporting standards

A total of 69,286 CT and 64,281 MRI examinations were performed in the participating institutions in 2019. Of the CT examinations, 30,682 (44\%) were performed at university hospitals, 


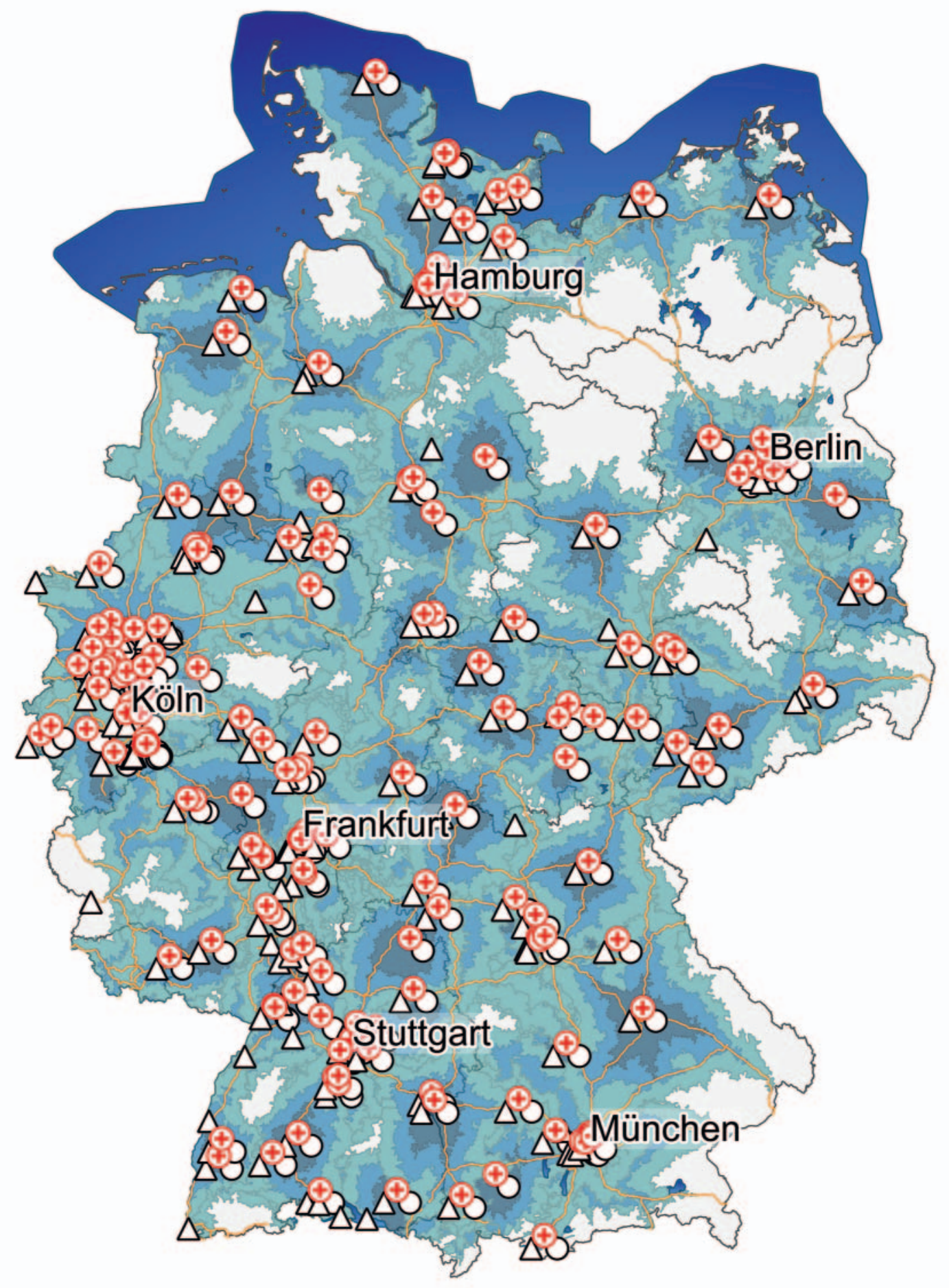

- Fig. 2 Overview of the centers certified for cardiovascular imaging (red crosses) in Germany in January 2021 and their corresponding catchment areas with a driving time of 30/45/60 minutes (dark blue/light blue/turquoise). Triangles represent CT Q2, and Q3 certified radiologists, circles MRI Q2, and Q3 certified radiologists. (Calculation of isochrones using openrouteservice, @ openrouteservice.org by HeiGIT I Map data @ OpenStreetMap contributors).

- Abb. 2 Übersicht über die für kardiovaskuläre Bildgebung zertifizierten Zentren (rote Kreuze) in Deutschland im Januar 2021 und ihre entsprechenden Einzugsgebiete in 30/45/60 Minuten Fahrzeit (dunkelblau/hellblau/türkis). Dreiecke stellen CT-Q2- und -Q3-zertifizierte Radiologen dar, Kreise MRT-Q2- und -Q3-zertifizierte Radiologen. (Berechnung der Isochronen mittels openrouteservice, @ openrouteservice.org by HeiGIT I Map data $\odot$ OpenStreetMap contributors). 


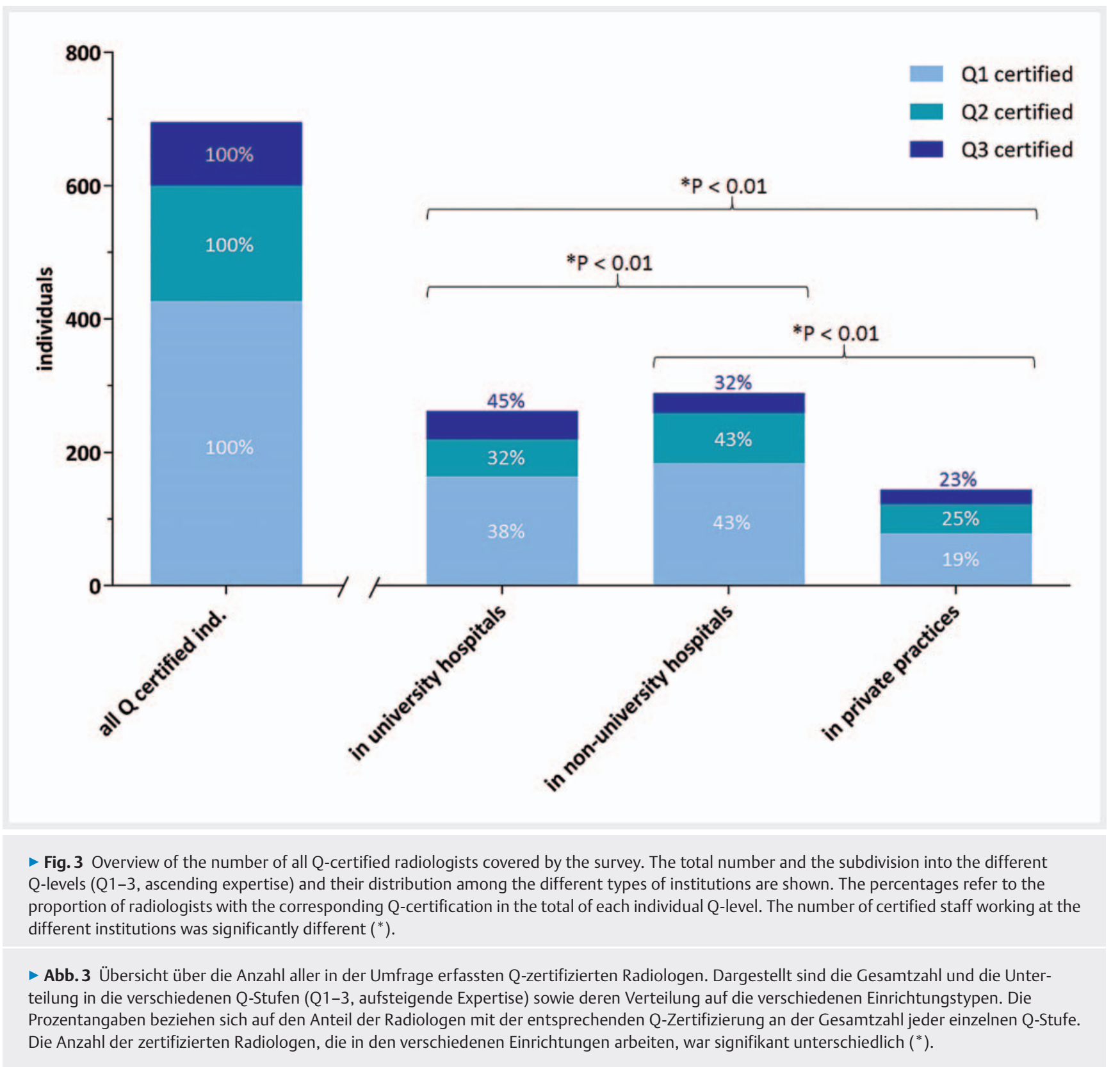

27,521 (40\%) at non-university hospitals, and 11,083 (16\%) at private practices. Of the MRI examinations, 22,630 (33\%) were performed at university hospitals, 28,151 (40\%) at non-university hospitals, and $13,500(20 \%)$ at private practices. The median number of examination was $610[459,1400]$ CT examinations and 525 [303, 911] MRI examinations performed at university hospitals, 213.5 [103.3; 471.3] CT examinations and 200 $[99,412] \mathrm{MRI}$ examinations at non-university hospitals, and 50 $[0,191]$ CT examinations and 23 [0, 149] MRI examinations at private practices in 2019. The data is illustrated in - Fig. 4.

In most institutions, reporting is either done solely by the radiologist or collaboratively with non-radiologists. CT examinations/ MRI examinations were reported by the radiologist alone in 106/ 85 institutions (74/59\%), in cooperation with non-radiologists (usually the referring physicians) in $37 / 52$ institutions (26/36\%), and exclusively by non-radiologists in $1 / 7$ institutions (1/5\%). This question was not answered by 40 institutions. A detailed description of reporting habits per modality/institution, and a comprehensive visualization of the data in this paragraph is provided in $\mathbf{F i g} \mathbf{5}$.

\section{Participation in the ESCR registry}

Overall, 88 institutions (48\%) documented their examinations in the ESCR registry. 38 institutions ( $40 \%$ ) indexed $1-25 \%$ of all their cardiac exams in the registry, each of 10 institutions (11\%) reported $26-50 \%$ and $51-75 \%$, and 37 institutions (39\%) 76-100\%. In proportion, $77 \%$ of university hospitals, $59 \%$ of non-university hospitals and $27 \%$ of private practices participated in the ESCR registry. A further, more detailed description of the data is presented in $>$ Fig. 6. 
a) CT exams

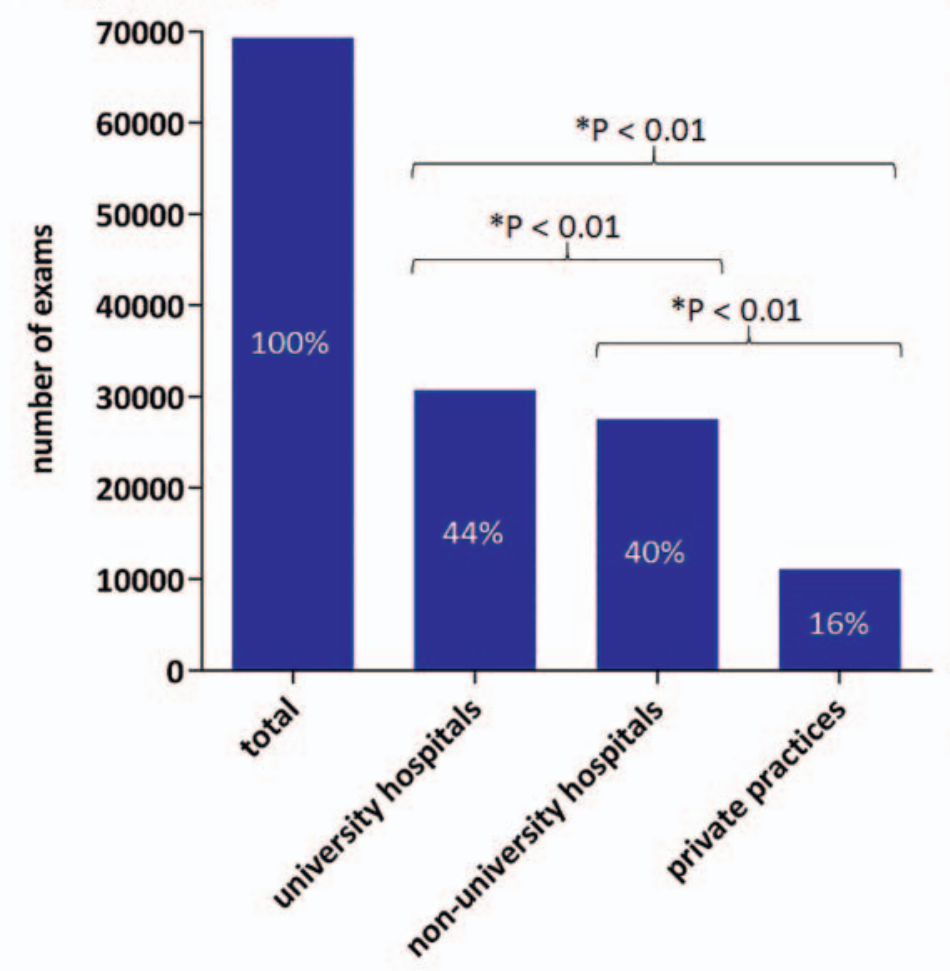

b) MRI exams

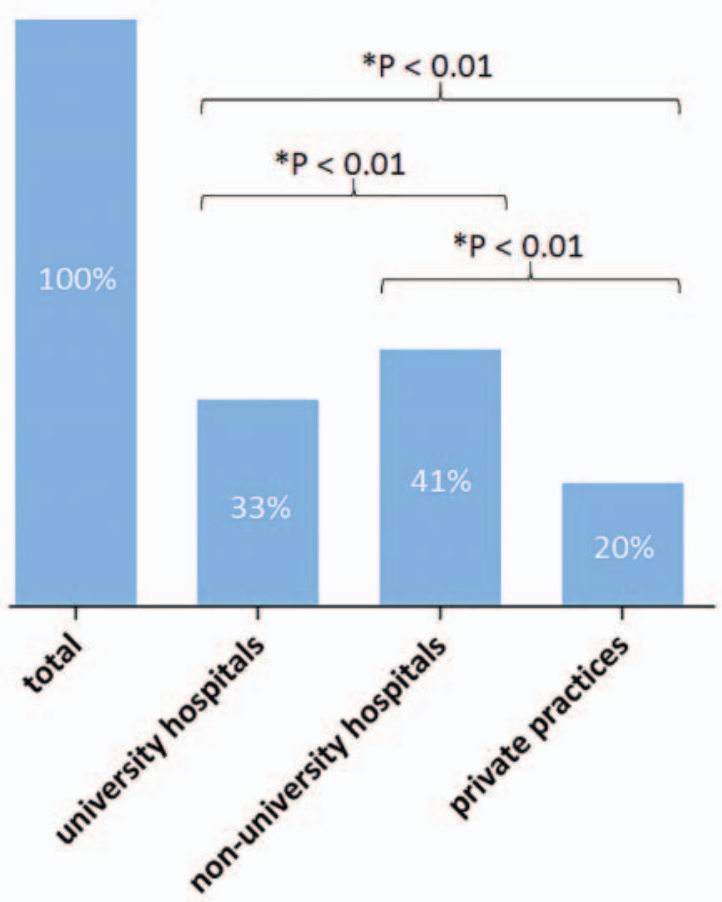

- Fig. 4 Summary of a cardiac CT and b MRI examinations performed at the participating institutions, in total and per institution type. The percentages refer to the proportion of examinations out of the total number per modality. The number of examinations for both modalities was significantly different $\left({ }^{*}\right)$ between all institutions. Below, the median for exams performed for each modality at each institution is given.

- Abb.4 Zusammenfassung der a kardialen CT- und b MRT-Untersuchungen, die in den teilnehmenden Einrichtungen durchgeführt wurden, insgesamt und pro Einrichtungstyp. Die Prozentangaben beziehen sich auf den Anteil der Untersuchungen an der Gesamtzahl pro Modalität. Die Anzahl der Untersuchungen für beide Modalitäten war zwischen allen Einrichtungen signifikant unterschiedlich $\left({ }^{*}\right)$. Im unteren Abschnitt der Abbildung ist der Median der durchgeführten Untersuchungen für jede Modalität in jeder Einrichtung angegeben.

\section{Communication with the DRG and the WG CVI}

The proposed topics were prioritized by the survey participants as follows: cooperation with colleagues $(n=34,43 \%)$, certification ( $n=48,61 \%)$, technology $(n=27,34 \%)$, medical education and training ( $n=50,63 \%)$. This question was skipped by 106 participants.

\section{Data from the ECSR Registry}

According to data from the ESCR registry, 181 German sites reported cardiac MR and 160 German sites also reported cardiac CT cases to the registry $(14,17)$, indicating that not all radiological sites performing cardiac CT und MRI in Germany and documenting their cases in the ESCR registry responded to the survey. The data concerning the reporting habits according to the registry can be found in $>$ Fig. 7 .

\section{Discussion}

In the present analysis, we describe the national availability and structural and interdisciplinary features of high-quality, certified cardiovascular imaging by radiological institutions across Germany. Our survey's key result is that there is nationwide availability of high-quality CVI in Germany by radiology specialists. Two facts mainly demonstrate this: Firstly, both certified centers and professionals provide specialized service with good accessibility within almost all regional clusters. Secondly, there is a high number of radiologists specialized and certified in CVI across all institutional types, with a continuing strong increasing development.

The special expertise has been promoted by a structured education program of the DRG as the basis for the certification of centers. The educational courses are taught at regular workshops and congresses (e.g., annual Congress of the ESCR, German Cardiodiagnostic Days (Deutsche Kardiodiagnostiktage - DKDT: https://www.kardiodiagnostik.de) and German Roentgen Congress), and by means of a comprehensive online program, both nationally and internationally. Also, the fully digitalized learning 


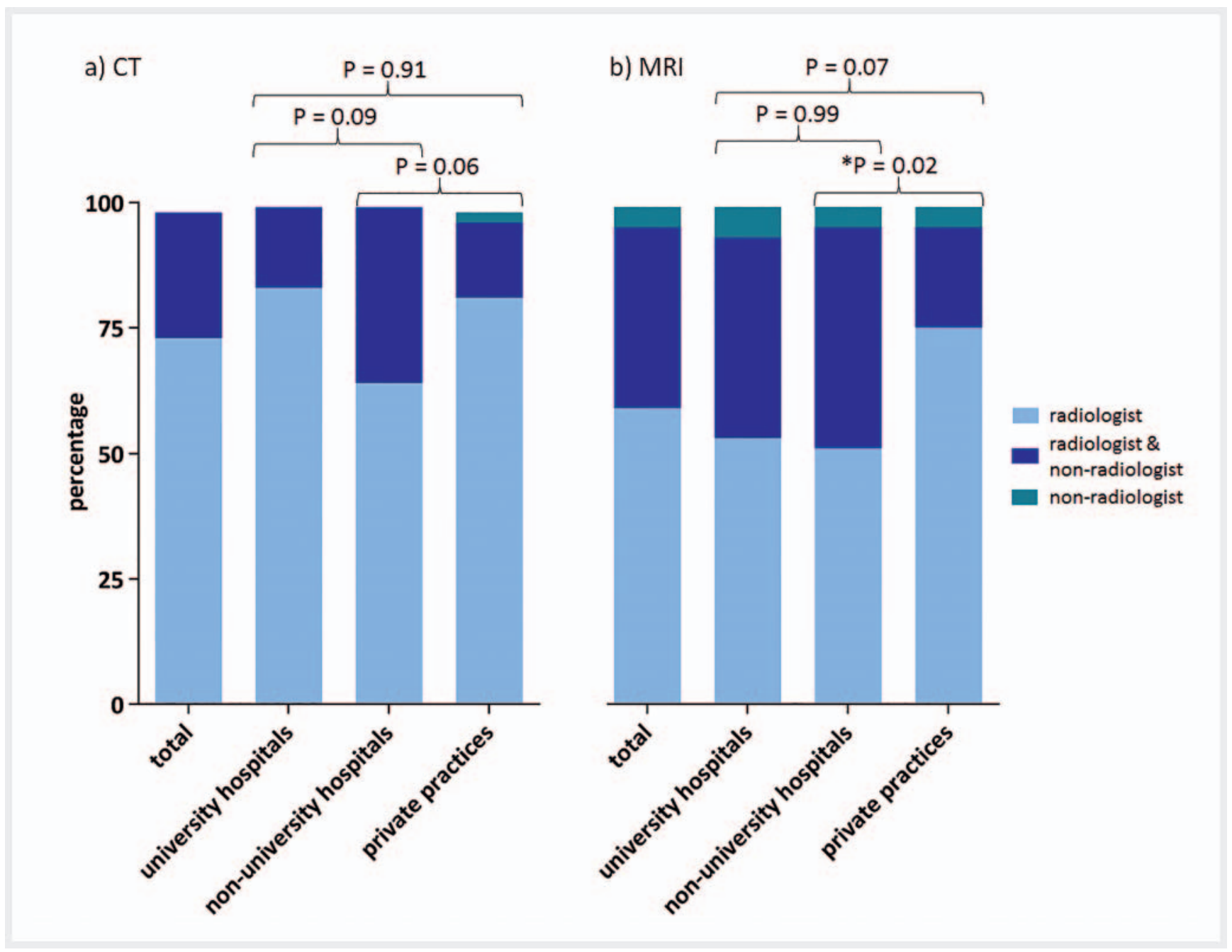

- Fig. 5 Overview of the reporting habits for $\mathbf{a}$ cardiac CT and $\mathbf{b}$ MRI in the surveyed institutions. Except for MRI reporting habits between non-university hospitals and private practices, there were no significant differences $\left({ }^{*}\right)$.

- Abb. 5 Übersicht über die Befundungsgewohnheiten für a kardiale CT und b MRT in den befragten Einrichtungen. Mit Ausnahme der MRT-Befundungsgewohnheiten zwischen den nichtuniversitären Krankenhäusern und den niedergelassenen Ärzten gab es keine signifikanten Unterschiede $\left({ }^{*}\right)$.

platform CONRAD (DICOM-data based), which includes a realistic, cardiovascular case-reading environment, has made it possible to provide educational content and continuation of the certification processes during the global COVID 19 pandemic restrictions. The steadily increasing number of certified centers and individuals as illustrated in $>$ Fig. 1 is also a strong indicator of an effective and successful subspecialization process.

Although a large number of examinations was performed regardless of the institution's structural character, there was a slight imbalance in favor of the university hospitals. However, the majority (56\%) of cardiac CT and MRI examinations in 2019 were performed at nonacademic institutions. This observation may be attributable to the following facts: i) As with all new and/or specialized medical developments, cardiac CT and MRI were usually introduced and evaluated at university hospitals first to demonstrate the clinical robustness and utility before widespread implementation took place. For cardiac CT and MRI, the transition from restricted local expertise to widely available expertise has successfully been accomplished, as demonstrated by data from the ESCR registry with growing numbers of non-university hospitals and medical practices. According to recent publications based on data of the ESCR registry, about $36 \%$ of cardiac MRI examinations in Europe were performed at academic and $64 \%$ at non-academic radiological centers [10-12].

Currently, there are 35 certified non-university centers and 36 certified university hospitals registered in Germany. Although the radiological community with its natural affinity for innovative imaging technologies has implemented a widespread service of high-quality CVI, a substantial impediment to increasing the number of examinations in private practice may be the limited reimbursement by the statutory health insurance funds. With regard to the high level of evidence for both cardiac CT and MRI illustrated by recently updated guidelines [1-3], full coverage of both modalities by statutory health insurance may be desirable. Nota- 


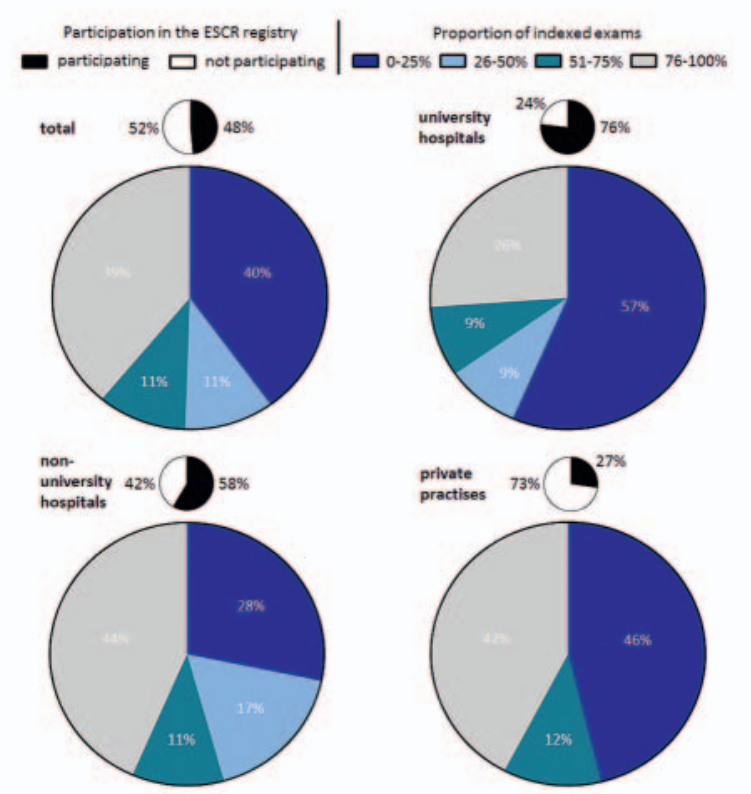

D Fig. 6 Percentage of the surveyed institutions participating in the ESCR registry, in total and per institution type, and proportion of examinations entered in the ESCR registry at the various institutions.

- Abb. 6 Prozentualer Anteil der befragten Einrichtungen, die am ESCR-Register teilnehmen, insgesamt und pro Einrichtungstyp, und Anteil der im ESCR-Register erfassten Untersuchungen an den verschiedenen Einrichtungen.

bly, the number of sites performing and submitting cardiac CT examinations to the ESCR registry in Germany increased from an already high number of 130 in 2018 to 160 in 2020 [13], emphasizing that radiological institutions are determined to provide the best possible medical care despite the limited reimbursement situation. CT and MRI of the cardiovascular system are still among the most technologically demanding applications of these modalities. Profound knowledge of the organ's pathophysiology and a high level of expertise in using the technology is required to ensure a high standard of patient care and clinical safety [14]. To guarantee this, the DRG offers a dedicated education curriculum with certification for technical staff [15]. CVI has not only been validated in detail by national and international radiological institutes but is also continually being further developed there. In terms of MRI, techniques such as T1 and T2 mapping are in the process of leaping from scientific application to clinical routine $[16,17]$, and new imaging acceleration techniques such as compressed sensing are showing their strengths in imaging a moving organ [18]. Considering CT, techniques such as myocardial CT perfusion and CT-derived fractional flow reserve promise to provide insight beyond simple anatomy imaging $[19,20]$. Here radiology has demonstrated its high innovation power regarding clinical and technical aspects, embracing new technology (e. g., artificial intelligence) whenever that benefits the patient.
It can be anticipated that radiology, as a bridging discipline with a high affinity for the technological and the medical field, can achieve its highest and most substantial contribution to medicine by combining broad clinical-medical knowledge with technical expertise. This expertise is the fundamental foundation to indicate and select the appropriate imaging technique and guarantees targeted, comprehensive diagnostics and therapeutics for each patient. Furthermore, an individual risk-benefit assessment in terms of radiation exposure is essential given the predicted increase in the use of advanced imaging techniques in clinical practice [8]. Against the background of demographic development and rising costs, it seems mandatory to maintain the four eyes principle ("Vier-Augen-Prinzip") with inclusion of a referring physician, e. g., a cardiologist, and a physician performing the diagnosis, i. e., the radiologist, in order to assure economic sustainability and efficiency in the German health care system [21]. For example, in a recently published randomized controlled trial of patients with an unclear NSTEMI diagnosis, initial cardiac MRI and coronary CTA provided non-coronary differential diagnoses, reduced the number of cardiac catheterizations, and led to a more appropriate referral to invasive procedures [22]. A meta-analysis demonstrated that coronary CTA was associated with a shorter length of stay in the emergency department and lower costs [23].

Our observation is that in most centers certified radiologists without direct interaction with non-radiology disciplines perform reporting of $\mathrm{CVI}$ exams, although there is a trend towards joint reporting in non-university hospitals, and for MRI compared to CT. It needs to be emphasized that especially the complex field of CVI clearly benefits from a regular exchange with disciplines outside of radiology to guarantee the highest possible medical quality. These observations are in line with the position statements of professional societies [24] and clinical reality as documented in the ESCR registry [12], in which consensus reading is practiced by approximately $20 \%$ of users in CT and approximately $30 \%$ in MRI ( $\triangleright$ Fig. 7). However, it cannot be ruled out that there are shadow reports of individual disciplines that are not consistent with the radiological report in certain aspects, creating uncertainties in patient treatment and medicolegal perspectives. There is no doubt that the interaction with colleagues from cardiology, pediatric cardiology, and cardiovascular surgery results in modification of clinical relevance and prioritizing, thereby benefiting the individual patient. This important interaction is practiced on a clinical level in joint interdisciplinary daily pre-TAVI meetings in the so-called Heart Team [25], joint consensus recommendations for cardiovascular imaging [26], and specialized congresses such as the "German Cardiodiagnostic Days". Another challenge is that CVI imaging is not restricted to a single organ or structure (e. g., coronary arteries) but also adjacent organs such as the lungs, breasts, and lymph nodes. For example, in a relevant number of cases with suspected NSTEMI, a different acute diagnosis was made on cardiac MRI [22], and in up to $44 \%$ of cases, incidental findings with potential clinical relevance were present in CVI [27]. Radiology has the broad medical expertise to correctly interpret these extracardiac findings. Furthermore, there is a strong need to establish processes that will handle the increasing demand for $\mathrm{CVI}$ and follow-up imaging that focused clinical disciplines cannot manage [28]. 
a) CT

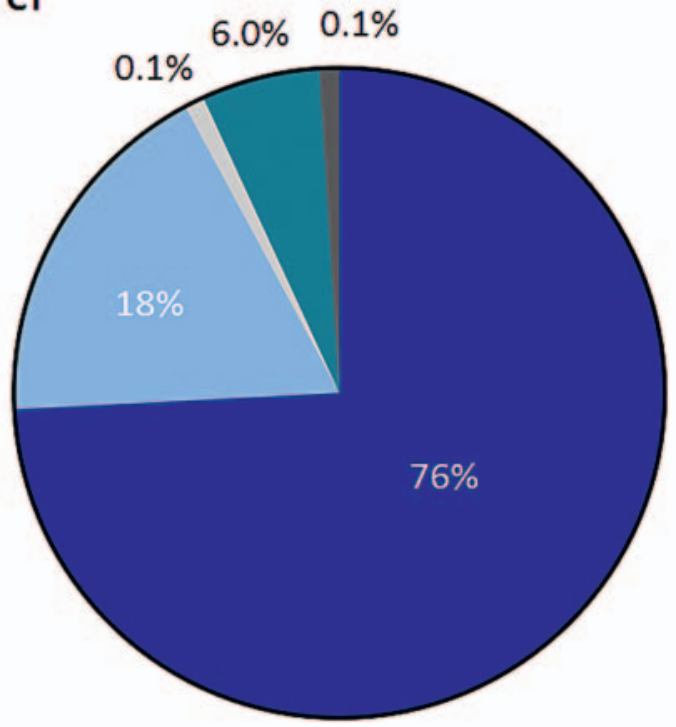

b) MRI

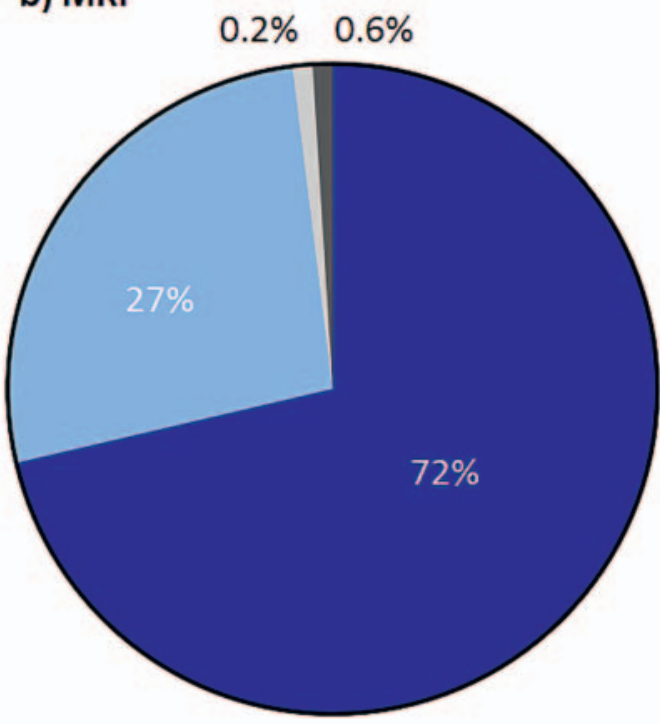

radiologist

- Fig. 7 Frequency of consensus versus single reading by radiologists and cardiologists of cardiac CT and MR examinations according to the ESCR Registry (modified from [10]).

- Abb. 7 Häufigkeit von Konsens- gegenüber Einzelbefundung durch Radiologen und Kardiologen bei kardialen CT- und MR-Untersuchungen nach dem ESCR-Register (modifiziert aus [10]).

Given the high relevance of interaction with various disciplines, including the central role of general practitioners within the German healthcare system, structured reporting is a tool with great potential to further improve interdisciplinary communication [29]. The WG CVI has already published templates for various cardiovascular pathologies and made them publicly available via an open-source license [30] and further implementation in clinical radiology service is highly recommended.

\section{Limitations}

The following limitations must be considered when evaluating this data collection: This survey does not cover all radiological institutions and is therefore only representative to a certain extent. For all non-certified or anonymous participants, a selection bias cannot be excluded, as an affinity for or particular interest in cardiac imaging could have influenced the willingness to participate. Furthermore, there is a relative predominance in favor of the university hospitals, which are included almost in their entirety, compared to the non-university hospitals and practices/ clinics that were not all surveyed.

\section{Conclusion}

This comprehensive analysis provides a detailed picture of the development and current status of radiological cardiovascular imaging in Germany in particular and in a European context, demonstrating that high-quality advanced cardiovascular ima- ging service by radiologists is available nationwide. Although a substantial number of non-university hospital and private practice-based radiologists perform cardiac CT and MRI, even wider availability may be hampered by insufficient reimbursement by statutory health insurance. A continued specialized education and certification system, a comprehensive radiology risk-benefit analysis, including assessment of radiation exposure and incidental findings, and increased interaction with relevant focused disciplines outside radiology is essential to accommodate the predicted substantial need for advanced cardiovascular imaging in the future and in the era of personalized medicine.

\section{CLINICAL RELEVANCE}

- "High-quality advanced cross-sectional cardiovascular imaging service by radiologists is available and accessible nationwide in Germany."

- "Highly qualified specialist knowledge in cardiovascular imaging is widely represented in university hospitals, nonuniversity hospitals, and private practices."

- "The national certification programs successfully contribute to the dissemination and deepening of advanced cardiovascular imaging expertise with a growing number of certified professionals and centers."

- "The ESCR registry is an established international tool for the documentation of cardiovascular imaging data." 


\section{Conflict of Interest}

The authors declare that they have no conflict of interest.

\section{References}

[1] Collet JP, Thiele H, Barbato E et al. 2020 ESC Guidelines for the management of acute coronary syndromes in patients presenting without persistent ST-segment elevation. Eur Heart J 2020. doi:10.1093/eurheartj/ ehaa575

[2] Knuuti J, Wijns W, Saraste A et al. 2019 ESC Guidelines for the diagnosis and management of chronic coronary syndromes. Eur Heart J 2020; 41: 407-477. doi:10.1093/eurheartj/ehz425

[3] [Anonym]. Bundesärztekammer (BÄK). Kassenärztliche Bundesvereinigung (KBV); Arbeitsgemeinschaft der Wissenschaftlichen Medizinischen Fachgesell- schaften (AWMF). Nationale VersorgungsLeitlinie Chronische KHK - Langfassung 2019. doi:10.6101/AZQ/000419

[4] Heseltine TD, Murray SW, Ruzsics B et al. Latest Advances in Cardiac CT. Eur Cardiol 2020; 15: 1-7. doi:10.15420/ecr.2019.14.2

[5] Kolentinis M, Le M, Nagel E et al. Contemporary Cardiac MRI in Chronic Coronary Artery Disease. Eur Cardiol 2020; 15: e50 doi:10.15420/ ecr.2019.17

[6] Haenel A, Stahlberg E, Sieren MM et al. [Computed tomography or cardiovascular magnetic resonance imaging for diagnosis of chronic coronary syndrome?]. Radiologe 2020; 60: 1114-1121. doi:10.1007/s00117-02000765-4

[7] Soschynski M, Taron ], Schlett CL et al. [Update on coronary CT-more than just anatomical imaging?: Current guidelines and functional CT techniques for the quantification of stenoses]. Radiologe 2020; 60: 1131-1141. doi:10.1007/s00117-020-00767-2

[8] Hirshfeld JW, Ferrari VA, Bengel FM et al. 2018 ACC/HRS/NASCI/SCAI/ SCCT Expert Consensus Document on Optimal Use of Ionizing Radiation in\&\#xa0;Cardiovascular Imaging: Best\&\#xa0;Practices for Safety and Effectiveness. J Am Coll Cardiol 2018; 71: e283-e351. doi:10.1016/ j.jacc.2018.02.016

[9] [Anonym]. Arbeitsgemeinschaft Herz- und Gefäßdiagnostik, Das Zertifizierungsprogramm 2021. Im Internet: https://www.ag-herz.drg.de/ de-DE/1201/ueberblick/

[10] [Anonym]. European Society of Cardiovascular Radiology (ESCR): https://www.mrct-registry.org - MRCT-Booklet.

[11] Uhlig J, Al-Bourini O, Salgado R et al. Gadolinium-based Contrast Agents for Cardiac MRI: Use of Linear and Macrocyclic Agents with Associated Safety Profile from 154779 European Patients. Radiology: Cardiothoracic Imaging 2020; 2: e200102 doi:10.1148/ryct.2020200102

[12] Uhlig J, Lucke C, Vliegenthart R et al. Acute adverse events in cardiac MR imaging with gadolinium-based contrast agents: results from the European Society of Cardiovascular Radiology (ESCR) MRCT Registry in 72839 patients. Eur Radiol 2019; 29: 3686-3695. doi:10.1007/s00330019-06171-2

[13] Matthias Gutberlet MD In: Claas Philipp Nähle MD ed. Email correspondence ed 2021

[14] Taylor A], Cerqueira M, Hodgson JM et al. ACCF/SCCT/ACR/AHA/ASE/ ASNC/NASCI/SCAI/SCMR 2010 Appropriate Use Criteria for Cardiac Computed Tomography. J Cardiovasc Comput Tomogr 2010; 4: 407. e401-407.e433. doi:10.1016/j.jcct.2010.11.001
[15] [Anonym]. Vereinigung technisch-medizinischer Berufe in der Deutschen Röntgengesellschaft e.V.. Curriculum. Fachkraft für Kardiovaskuläre Bildgebung 2021. In. https://www.vmtb.de/de-DE/4717/fachkraftfuer-kardiovaskulaere-bildgebung/

[16] Radenkovic D, Weingärtner S, Ricketts L et al. T(1) mapping in cardiac MRI. Heart Fail Rev 2017; 22: 415-430. doi:10.1007/s10741-017-9627-2

[17] Hanson CA, Kamath A, Gottbrecht M et al. T2 Relaxation Times at Cardiac MRI in Healthy Adults: A Systematic Review and Meta-Analysis. Radiology 2020; 297: 344-351. doi:10.1148/radiol.2020200989

[18] Bustin A, Fuin N, Botnar RM et al. From Compressed-Sensing to Artificia Intelligence-Based Cardiac MRI Reconstruction. Front Cardiovasc Med 2020; 7: 17 doi:10.3389/fcvm.2020.00017

[19] Seitun S, Clemente A, De Lorenzi C et al. Cardiac CT perfusion and FFR (CTA): pathophysiological features in ischemic heart disease. Cardiovasc Diagn Ther 2020; 10: 1954-1978. doi:10.21037/cdt-20-414

[20] Gutberlet M, Krieghoff C, Gohmann R. [Is FFRCT a game changer in coronary CT angiography?]. Herz 2020; 45: 431-440. doi:10.1007/ s00059-020-04944-w

[21] Hillman B], Joseph CA, Mabry MR et al. Frequency and costs of diagnostic imaging in office practice-a comparison of self-referring and radiologistreferring physicians. N Engl J Med 1990; 323: 1604-1608. doi:10.1056/ NEJM199012063232306

[22] Smulders MW, Kietselaer B, Wildberger JE et al. Initial Imaging-Guided Strategy Versus Routine Care in Patients With Non-ST-Segment Elevation Myocardial Infarction. J Am Coll Cardiol 2019; 74: 2466-2477. doi:10.1016/j.jacc.2019.09.027

[23] Hulten E, Pickett C, Bittencourt MS et al. Outcomes after coronary computed tomography angiography in the emergency department: a systematic review and meta-analysis of randomized, controlled trials. J Am Coll Cardiol 2013; 61: 880-892. doi:10.1016/j.jacc.2012.11.061

[24] The SBoT. Clinical practice of cardiovascular magnetic resonance: position statement of the Society for Cardiovascular Magnetic Resonance. J Cardiovasc Magn Reson 2019; 21: 78 doi:10.1186/s12968-019-0592-x

[25] Francone M, Budde RP], Bremerich J et al. CT and MR imaging prior to transcatheter aortic valve implantation: standardisation of scanning protocols, measurements and reporting-a consensus document by the European Society of Cardiovascular Radiology (ESCR). Eur Radiol 2020; 30: 2627-2650. doi:10.1007/s00330-019-06357-8

[26] Sommer T, Bauer W, Fischbach K et al. MR Imaging in Patients with Cardiac Pacemakers and Implantable Cardioverter Defibrillators. Rofo 2017; 189: 204-217. doi:10.1055/s-0043-102029

[27] Flor N, Di Leo G, Squarza SA et al. Malignant incidental extracardiac findings on cardiac CT: systematic review and meta-analysis. Am J Roentgenol 2013; 201: 555-564. doi:10.2214/Am J Roentgenol.12.10306

[28] He BJ, Malm BJ, Carino M et al. Prevalence and variability in reporting of clinically actionable incidental findings on attenuation-correction CT scans in a veteran population. J Nucl Cardiol 2019; 26: 1688-1693. doi:10.1007/s12350-018-1232-9

[29] Pinto Dos Santos D, Hempel JM, Mildenberger P et al. Structured Reporting in Clinical Routine. Rofo 2019; 191: 33-39. doi:10.1055/a-0636-3851

[30] Bunck AC, Baeßler B, Ritter C et al. Structured Reporting in Cross-Sectional Imaging of the Heart: Reporting Templates for CMR Imaging of Cardiomyopathies (Myocarditis, Dilated Cardiomyopathy, Hypertrophic Cardiomyopathy, Arrhythmogenic Right Ventricular Cardiomyopathy and Siderosis). Rofo 2020; 192: 27-37. doi:10.1055/a-0998-4116 